\title{
Motivational mechanisms and schedule-induced behavioral stereotypy
}

\author{
VASSILIKI PAPADOUKA and T. JAMES MATTHEWS \\ New York University, New York, New York
}

\begin{abstract}
In two experiments, behavioral stereotypies elicited by scheduled presentations of food and water were compared. In Experiment 1, pigeons were exposed to a fixed-time 30-sec (FT 30-sec) schedule of food or water deliveries with a brightening keylight stimulus signaling time to the unconditioned stimulus (UCS) on each trial. Food and water presentations both produced terminal autoshaped keypecking that was similarly distributed in the trial but differed in response topography and persistence. Locomotor interim behavior was different in the two motivational conditions: With food presentations, it consisted of a "retreat" to the rear of the chamber after UCS termination, followed by "pacing" in the midportion of trials. The water schedule produced very little locomotor activity with no regular distribution in the trial. Experiment 2, using a random-time 30-sec (RT 30-sec) schedule, showed that the differences in interim locomotor behavior persisted in the absence of temporal predictability of the UCS and the keypecking terminal response. The results are taken to support Timberlake's (1983a) behavior-system theory.
\end{abstract}

The simple procedure of presenting brief unconditioned stimuli (UCSs) to freely moving subjects at fixed intervals has been observed to result in the emergence of a wide variety of behaviors. Despite the fact that these behaviors are not supported by an explicit operant reinforcement contingency, they are persistent, vigorous, and rather reliable in their form. Staddon and Simmelhag (1971) termed those behaviors "schedule-induced" and divided them into "terminal" behaviors, which resemble the consummatory response and tend to occur near the end of the interstimulus interval (ISI), and "interim" behaviors, which occur earlier in the ISI and have a less consistent form. The former behaviors are certainly inclusive of traditional Pavlovian conditioned responses, and the latter have also been called "adjunctive behavior" (Falk, 1971). Although terminal behaviors are fairly well understood, interim behaviors have resisted a simple characterization.

Falk (1977) suggested that adjunctive behavior serves a stabilizing function at times when the behavioral expression of the dominant drive is thwarted. In those situ-

This research was supported in part by NIH Grant BRSG 2-S07-RR07062 awarded to the second author. The work was part of the first author's doctoral dissertation in the Experimental Psychology Program of the Department of Psychology at New York University. The authors would like to acknowledge the assistance of Laura Bayer, Carolyn Flaster, and Jonathan Navon in the collection of data. V.P. is now at the Millhauser Laboratories, New York University Medical Center, 550 First Avenue, New York, NY 10016. T.J.M. is also affiliated with the Center for Neural Science at NYU. Requests for reprints should be sent to T. J. Matthews, Department of Psychology, New York University, 6 Washington Place, New York, NY 10003 (e-mail: tjm@xp.psych. nyu.edu).

-Accepted by previous editor, Vincent M. LoLordo ations, animals have a tendency to leave the site, but adjunctive behavior prevents escape, enhancing the likelihood that the dominant drive will be satisfied. Falk considered this behavior as a third class of behavior that did not fit the operant or the Pavlovian scheme.

In observing pigeons' behavior in response to scheduled food presentations, Staddon and Simmelhag (1971) proposed that interim behavior was a result of an adaptive tendency of behavior to proliferate in variable forms when the behaviors dictated by the dominant drive state were prevented from occurring. This mechanism would enable other drive states to emerge and other UCSs in the situation to be taken advantage of. It would ensure that the animal would "not linger in the vicinity of food (or other reinforcers) at times when it [was] not available" (p. 38) and would miss opportunities to satisfy other needs while the one in question was blocked. The difference between the two theories above is that in Falk's account interim activity serves to keep the animal in the situation, whereas in Staddon and Simmelhag's theory it serves to take the animal out of an unpromising situation, allowing for the satisfaction of other motivational needs.

Both Falk's and Staddon and Simmelhag's theories assume that interim behavior is not related to the appetitive stimulus but involves motivational mechanisms other than the one that relates to the UCS. Timberlake (1983a) and Timberlake and Lucas (1985) suggested that interim behavior was part of the behavior system that is activated in the particular experimental situation. The theory, which is called the "behavior-system" approach, holds that a motivational system consists of "preorganized behavioral components and stimulus sensitivities" (Timberlake \& Lucas, 1985, p. 297). Upon activation of that system, these already existing patterns of behavior are likely to emerge when stimuli in the experimental envi- 
ronment are physically similar to eliciting stimuli in the natural environment or when those stimuli are similar to naturally occurring stimuli in their temporal relation to the UCS. In the latter respect, the behavior-system theory accounts well for the troublesome fact that the form of Pavlovian conditioned responses is often quite different from the consummatory response.

The single-motivation account of food-induced stereotypy has also been proposed by Staddon and Ayres (1975) and Staddon (1977). Innis, Simmelhag-Grant, and Staddon (1983) suggested that one motivational state dominates the ISI and that interim behavior might reflect the appetitive phase of the food state.

One way to resolve these disagreements would be to study schedule-induced behavior under motivational states other than hunger. According to the behavior-system approach, different motivational systems consist of different behavioral modules and, hence, would be expected to produce different interim and terminal behavior forms. On the other hand, according to Staddon and Simmelhag (1971) and Falk (1977), interim behavior should be similar with different UCSs presented in similar situations, because the interim "state" reflects increased responsiveness to other UCSs in the environment. The present research compared interim and terminal behavioral patterns that develop in response to intermittent presentations of food and water.

\section{EXPERIMENT 1}

Few studies have explored interim and terminal behavior using water as the appetitive stimulus. This work suggests that, as with food UCSs, terminal behavior also develops with water UCSs but often its form is different (Boakes, Poli, Lockwood, \& Goodall, 1978; Davey \& Cleland, 1982; Timberlake, 1983b). With pigeons, Jenkins and Moore (1973) reported that the topography of autoshaped keypecking differs in response to food and water presentations in a way that resembles the consummatory response: food-induced pecks are more forceful, open-beaked, and of shorter duration, whereas waterinduced pecks are slower, sustained, and closed-beak, and often occur together with swallowing movements. The topography of food- and water-induced terminal responding is also thought to depend on the nature of the signaling stimulus and its interaction with the motivational condition (Timberlake, 1983b).

With few exceptions (Bellingham, Wayner, \& Barone, 1979; King, 1974), the studies that have examined interim behavior using water as the appetitive stimulus suggest that intermittent water presentations do not induce excessive feeding, wheel running, or other activities in rats (Campbell \& Oei, 1986; Carlisle, Shanab, \& Simpson, 1972; Reid, Vazquez, \& Rico, 1985; Timberlake \& Lucas, 1991; Wetherington \& Riley, 1985). With pigeon subjects, Reberg, Innis, Mann, and Eizenga (1978) compared behavior induced by fixed-time 15 -sec (FT 15-sec) schedules of food and water. With water pre- sentations, the pigeons tended to remain near the water source through the trial; in food sessions, they were more active, often leaving the hopper area after they had consumed the food and then clearly exhibiting terminal behavior a few seconds before the hopper was presented. Innis, Reberg, Mann, Jacobson, and Turton (1983) reported similar findings using longer FT schedules, and suggested that, on water trials, subjects seem to remain in a "water state" through the ISI, whereas early on food trials, they are in a "nonfood" state and so leave the hopper area and engage in other activities.

Allan and Matthews (1989) studied food and water UCSs on FT 30-sec schedules and measured locomotor interim behavior with a floorboard similar to the one used in the present experiments. In the food condition, they reliably observed a "retreat" to the rear of the chamber early in the ISI and "pacing" during the midportion of the trial. In the water condition, however, retreat and pacing were much reduced. Although these results are in agreement with those of Reberg et al. (1978) and Innis et al. (1983), Allan and Matthews also found that, on water trials, pigeons tended to linger at the rear of the chamber rather than toward the UCS source at the front as previously reported.

Allan and Matthews (1989) also reported that the form and vigor of behavior established under one motivator can "carry over" to the behavior observed under a second motivator. Specifically, when animals were first exposed to the water procedure, activity in the rear of the chamber was quite high, and when they were switched to the food condition, high activity in the rear of the chamber was maintained, although it was modified in terms of temporal distribution. One implication of carry-over effects could be that the form and distribution of interim behaviors are not as exclusively traceable to the supporting motivational mechanism as the behavior-system view would predict (Timberlake, 1983a).

The purpose of the present work was to resolve these inconsistencies and provide a more complete characterization of terminal and interim behavior. Interim behavior was defined as locomotor activity measured by a segmented floorboard (similar to that used by Allan \& Matthews, 1989, and Matthews \& Lerer, 1987). To add a measure of terminal behavior, we used autoshaped keypecking to a brightening keylight stimulus "ramp" (Ferster \& Skinner, 1957; Matthews \& Lerer, 1987), which signaled time to the UCS presentation. Unlike traditional discrete-trial procedures, this continuous ramp procedure leaves the subject free to initiate responding at any time in the trial, allowing for a more sensitive estimate of the point at which the subject enters the terminal state.

\section{Method}

\section{Subjects}

Six mature male White Carneaux pigeons were used. When run in the water procedure, the subjects were deprived of water for $48 \mathrm{~h}$ before the experimental session and had free access to water for $24 \mathrm{~h}$ after the session. Food was freely available in their home 
cages. When run in the food procedure, the subjects were at $80 \%$ of their free-feeding weights and had free access to water. Because the food given in the experimental session was not sufficient to maintain their reduced weights, supplementary feedings were given within $2 \mathrm{~h}$ following the session. All animals were housed individually under a 12:12-h light:dark cycle.

\section{Apparatus}

The subjects were tested in a $49 \times 35 \times 38 \mathrm{~cm}$ chamber located in a sound-at1enuated room. Illumination was provided by a $60-\mathrm{W}$ light mounted $1 \mathrm{~m}$ above the hopper wall outside the chamber. The front wall consisted of a standard Grason-Stadler intelligence panel that contained the food hopper or water dipper. The hopper opening was located $10 \mathrm{~cm}$ above the floor. In food sessions, reinforcement consisted of a 3-sec presentation of mixed grain. In water sessions, the animals also had a $3-\mathrm{sec}$ access to water. Water was presented in a cylindrical cup, $1.5 \mathrm{~cm}$ in diameter and $1 \mathrm{~cm}$ deep, that held $1.8 \mathrm{cc}$ of water. The cup was filled every time it was lowered after reinforcement termination into a water reservoir located below. During the 3-sec presentation of the UCS, the opening was illuminated by a 9 -W light. A transparent test-chamber ceiling allowed for video monitoring. Experimental events were programmed and recorded by a remotely located computer.

The response key. The transiucent response key, $2 \mathrm{~cm}$ in diameter, was located $22.5 \mathrm{~cm}$ above the floor on the same wall that contained the hopper or the dipper. Four LED square light bars located behind the key provided its illumination. The brightness of the key was varied by altering the proportion of a $60-\mathrm{Hz}$ cycle, during which power was applied to the LEDs (pulse-width modulation). On each trial, the brightness incremented I pulse-duration step every $.3 \mathrm{sec}$, through a logarithmic series of 100 pulse durations. All trials started with a 0 -sec pulse duration and ended with a $16.7-\mathrm{msec}$ pulse duration, which provided continuous illumination of the key.

Floorboard. Locomotor activity was measured by a floorboard consisting of nine $16 \times 11.4 \mathrm{~cm}$ Plexiglas panels arranged in a $3 \times$ 3 array. Panel depression was detected by four microswitches at the corners of each panel. The floorboard was covered with a protective plastic sheet.

\section{Procedure}

F-W Group. Three subjects $(6,7$, and 8 ) were first exposed to the food procedure. During the first 1 or 2 sessions, the subjects were trained to eat from the hopper. The animals were then exposed to 15 sessions in which 21 UCSs were presented on an FT $30-\mathrm{sec}$ schedule. The keylight was added which signaled the remoteness of the UCS in time on each trial.

Following a $31 / 2$-week suspension of testing and deprivation, the water condition was begun. The animals were deprived of water for $48 \mathrm{~h}$ and were magazine trained to drink from the dipper. After 2-5 days of magazine training, the birds were exposed to 15 sessions with 21 water UCSs presented on an FT $30-\mathrm{sec}$ schedule accompanied by the keylight stimulus described above. About $30 \mathrm{~min}$ after testing, the animals were given free access to water for $24 \mathrm{~h}$, followed by $48 \mathrm{~h}$ of deprivation before the next session. Thus, the animals were tested every 3 rd day.

W-F Group. Three subjects (11, 13, and 15) were exposed to exactly the same procedure as were the animals in the F-W group but in reverse order. That is, these subjects were first exposed to the water schedule for 15 sessions. After about $31 / 2$ weeks of rest, during which they had free access to food and water, they were food deprived to $80 \%$ of their free-feeding weights and were run on the food schedule for 15 sessions.

\section{Results}

First, the within-trial rate and distribution of front and rear activity in the trial were examined. Front activity was defined as movement across the three front panels of the floorboard (with respect to the UCS location); rear activity was defined as movement across the six middle and rear panels. Figure 1 represents within-trial rates of front and rear locomotion as well as keypecking averaged over the first 10 trials of the last five sessions of each motivational condition for each bird. Analysis was restricted to the first 10 trials because we had found that pecking behavior was markedly reduced in the latter portion of the water sessions.

In the food phases, animals in both groups showed similar distributions of activity and keypecking within the trial. Immediately following reinforcement, activity was concentrated in the rear. Front-panel activity peaked at about the middle of the interval. Between the 7 th and 17th bins, keypecking was detected at low levels, with maximum rates observed during the last few bins of the trial. In the water phases, activity was quite low and was almost exclusively confined to the first part of the trial and to the front of the chamber. As in the food phases, keypecking was negligible until the midpoint of the trial and maximal in the last few seconds of the trial. Unlike the food phases, however, keypecking response rate did not level off at the end of the trial.

The most impressive difference between the two motivational conditions was the almost complete absence of floor-panel activity under the water schedule. Statistical comparison of rates of activity (panel closures/second, front and rear) in the water and food conditions using a Wilcoxon matched-pairs signed-ranks test showed a significant difference $(T+=2 \mathrm{l}, p<.015)$.

Overall, it appears that the within-trial initiation and distribution of pecking behavior was quite similar in the two motivational conditions. Despite these similarities, however, further analyses revealed some differences. First, keypecking rate as a function of trials within the session was examined. The upper panel of Figure 2 represents mean keypecks per trial for all 20 trials of the last five sessions of each motivational condition averaged over subjects. Pecking decreased consistently over the session in the water phases for both groups, but decreased only very little in the food phases. The slopes of the water phases were significantly steeper than those of the food phases (Wilcoxon matched-pairs signed-ranks test on slopes of linear fits, $T+=21, p<.015$ ). Although rates of pecking seemed to be higher in the second phases of both groups regardless of the motivational condition, Mann-Whitney tests revealed that the activity rates were higher for the Phase 2 water condition (Group F-W) than for the Phase 1 water condition (Group W-F) ( $n 1=n 2=3, U=0, p<.05$ ), but the two food groups did not differ $(U=4, p<.83)$.

The decline in rate in the water condition was the result of a gradual slowdown in rate over the session, not an averaging artifact over sessions in which pecking stopped abruptly after various numbers of trials. The birds stopped pecking toward the end in only 8 of the 30 sessions analyzed. Rather, it appears that the primary factor in the rate decline was an increase in the latency to initiate pecking within each trial. The middle panels 


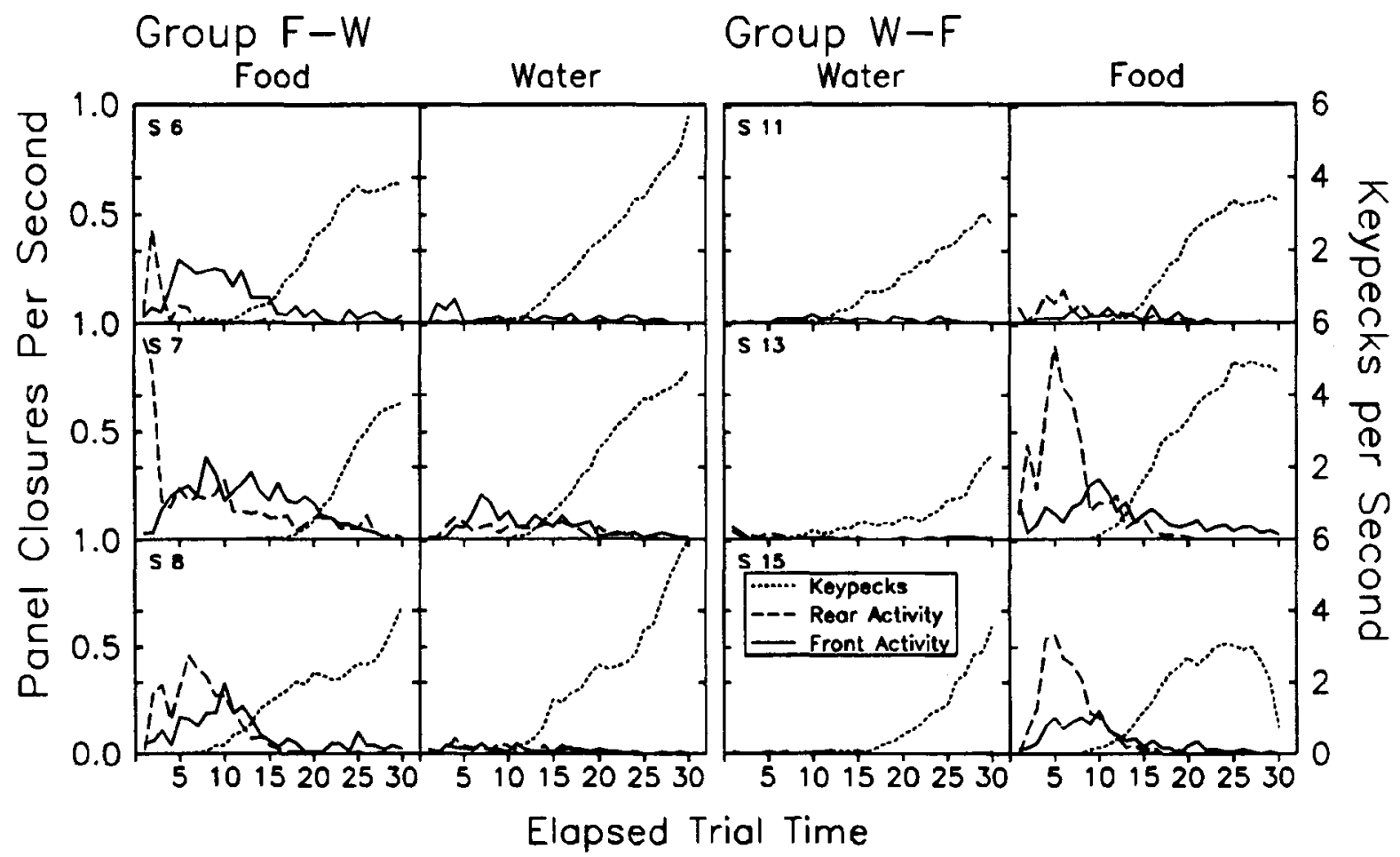

Figure 1. Rates of front and rear activity (panel closures/second) and keypecking, plotted as a function of elapsed time in the trial (30 sec), for each of the subjects in the F-W and W-F groups in both motivational conditions. Each graph represents an average of the first 10 trials of each of the last five sessions (Sessions 11-15) in each condition.

of Figure 2 show the mean latency to initiate pecking as a function of trials within the session. The functions are averaged over subjects and over the last 5 days of each condition. The water condition produced steeper slopes than the food condition in both groups (Wilcoxon matchedpairs signed-ranks test, $T+=21, p<.015$ ). The lower panel presents the mean rate of responding following the first response on those trials in which more than one response occurred. While latencies in the water conditions increased through the session, the rate of responding following the first response (lower panels) appears to be relatively stable in both food and water phases.

Another interesting difference between food and water pecking behavior concerned the pattern of pecking. Once initiated, pecking in the food condition was evenly paced, whereas pecking in the water condition consisted of bursts of rapid pecking. In fact, the proportion of very short interresponse intervals (less than $.2 \mathrm{sec}$ ) was higher for all animals in the water phase (Wilcoxon test, $T+=21, p<.015$ ). Jenkins and Moore (1973) reported that food-elicited pecks were more discrete and forceful, with the animal moving its head back before it "hammered" the key, whereas, in anticipation of water, subjects "nuzzled" the key. Thus, birds in the water condition may have been holding the response key close to the trigger point of the switch and jittering it to produce faster pecks than would be possible with the hammering topography.
Since activity induced by the water schedule was higher for the subjects with initial exposure to the food condition, and since pecking was also more persistent following exposure to the food schedule, phase order effects may have been present. It is possible, however, that these effects were not the result of carry-over from the food condition, but of the more prolonged exposure to the schedule of UCS deliveries in Phase 2 for Group F-W. It may be that to reach full strength water stereotypies are slower than food stereotypies. Prior exposure to the water condition did not seem to carry over to the subsequent food condition.

\section{Discussion}

Intermittent water and food presentations both elicit autoshaped keypecking to a stimulus that signals the onset of the UCS. The similarity of food and water conditions with respect to the temporal distributions of pecking would seem to discourage the sustained "waterstate" interpretation offered by Innis et al. (1983). From the comparable points of initiation of pecking, it would appear that animals enter the "terminal" state at approximately the same point in the trial.

The increase in latency to peck over trials shown in the water conditions but not in the food conditions seems to imply that satiation was occurring within sessions. Contrary to this interpretation, however, the birds continued to consume the water UCSs until the end of the session. 


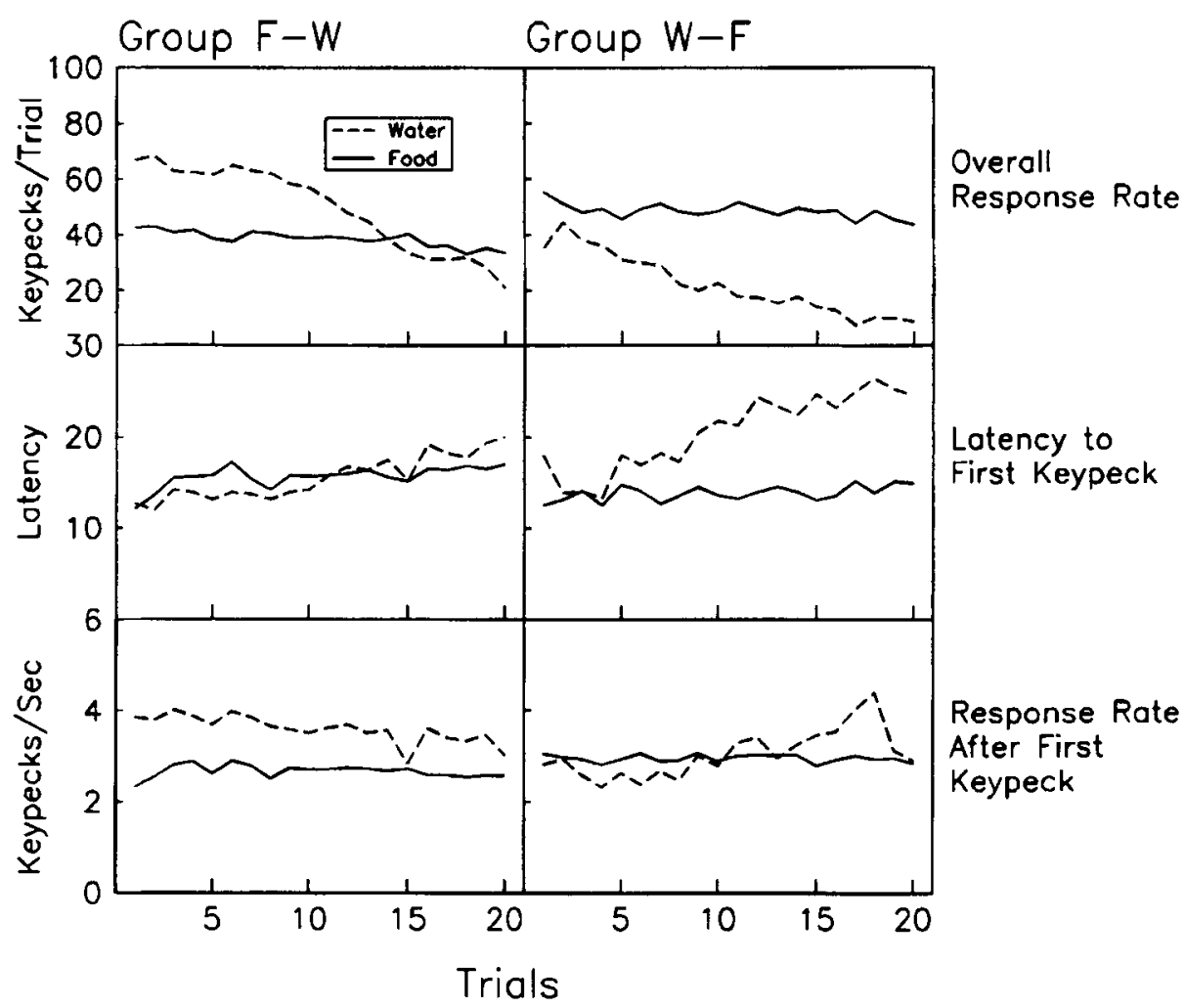

Figure 2. The right and left columns represent averages over all subjects for the last five sessions for Groups F-W (left) and W-F (right). The upper panels show overall response rates, the middle panels show the latency to the first keypeck, and the lower panels represent the rate of response following the first response on those trials in which more than one response occurred, all for the food and water conditions.

Davey and Cleland (1982) have also reported that rats under 24-h water deprivation continued to drink but ceased contacting a CS signaling water.

That satiety may not have been central to the reduction in keypecking across the water sessions is further indicated by the present observation that birds lost at least $40 \mathrm{~g}$ during the 48 -h deprivation period but drank only 10-20 g during the session. Furthermore, all animals drank about $40 \mathrm{~g}$ of water when they were given free access $30 \mathrm{~min}$ after the test session.

Although it remains possible that autoshaped keypecking is supported only by acute water deprivation, a behavioral explanation might adequately account for the decrease in pecking in the water sessions. From a behavior-system perspective (Timberlake, 1983a; Timberlake \& Lucas, 1985), water anticipatory behavior may not be very persistent for pigeons. In comparison with food availability in the natural environment, water is usually easily found (especially from the air) and is typically in generous supply when located. Sustained approach to a small supply such as that provided on our FT 30 -sec schedule could do more to draw predatory attention than to defend hydration.

The differences between food- and water-induced behavior were more pronounced with respect to interim behavior. Food presentations typically elicit retreat, vigorous pacing, and robust keypecking. Both retreat and pacing were almost completely absent with water presentations in the initial water condition and minimal in the water condition that followed the food condition. This observation is in accordance with that of Innis et al. (1983) and Reberg et al. (1978), who also found that their subjects almost never spent any time away from the water area, but is in disagreement with Allan and Matthews (1989), who observed persistent retreat in the water condition. This difference may be related to procedural differences with respect to the control of the motivational levels. Allan and Matthews used a very severe deprivation condition ( $48 \mathrm{~h}$ with no after-session drinking) and did not allow sufficient time between Phases 1 and 2 for the Phase 1 deprivation condition to dissipate.

Although it remains possible that more vigorous interim behavior may have emerged had there been more extended training or had the water-deprivation level been more severe, the present comparison is based upon similar levels of motivation, as indicated by the robustness of pecking in the food and water conditions. These data encourage the behavior-system view (Timberlake, 1983a) that suggests that the form of behavior is extracted from the natural patterns associated with the motivational mechanism. In nature, foraging for food involves withdrawal of the animal from a food-depleted area followed by vigorous searching movements in a new location. Water seeking by pigeons, however, does not involve 
such movement patterns, since the water source is usually not depleted before satiation.

Phase-order effects (Allan \& Matthews, 1989; Boakes et al., 1978; Reberg et al., 1978) may have been observed in this experiment. Pecking and, to a lesser extent, interim behavior were elevated following exposure to the food condition. This may have been due to the extended training associated with the postfood water condition, but if that were the case, a similar effect would have been expected for the early- and late-food conditions. It is more likely that well-formed interim and terminal behaviors have a "momentum" (Nevin, 1984) that influences behavior in similar circumstances.

Before concluding that water presentations do not actually induce locomotor interim behavior, the role of the experimental procedure should be examined. It is possible that the temporal predictability of the UCS and the frontal location of the ramp stimulus may have had the effect of keeping the subjects near the front, thus interfering with the expression of interim behavior. Indeed, Matthews, Bordi, and Depollo (1990) have shown that pacing behavior increases sharply when both temporal and ramp signal predictability of food UCSs are removed. In the next experiment, unsignaled and temporally random UCSs were used to enhance the likelihood of observing interim behavior in the water conditions.

\section{EXPERIMENT 2}

Most studies of interim behavior, including Experiment 1 , have used FT schedules of food and water delivery. On these schedules, retreat and keypecking tend to occur early and late in the interval and have been associated with low and high UCS probability. Matthews et al. (1990) have shown that when predictability is removed by presenting food to pigeons on a random-time schedule (RT), both retreat and keypecking are greatly reduced. Pacing, which tends to occur in the midportion of FT intervals, is not diminished by RT schedules. Rather, it expands to fill the total interval and therefore has a much higher frequency than it does on FT schedules. On the basis of this distinction, Matthews et al. described pacing as a "kinesic" behavior that results from repeated presentations of food but is competitively excluded by behavior tied to local variations in UCS probability. Retreat and keypecking, on the other hand, are "taxic" behaviors and are tied to local periods of low and high UCS probability, respectively.

One implication of the above reasoning is that pacing behavior might be differentially suppressed on FT schedules depending on the motivational mechanism in effect. Although food UCSs produce kinesic pacing on both signaled and unsignaled FT schedules, some unmeasured taxic behavior, such as "hopper tending," may perhaps be present with water UCSs that effectively suppresses pacing. Accordingly, Experiment 2 compared food and water UCSs under RT schedules with the expectation that pacing might be more conspicuous in the absence of taxic behaviors.

\section{Method}

\section{Subjects}

The subjects were 6 mature male White Carneaux pigeons (F-W group, 91, 93, 95; W-F group, 97, 98, 2). The subjects were treated exactly as in Experiment 1.

\section{Apparatus}

The apparatus used was the same as that used in Experiment 1. No keylight stimulus was present during testing at any time.

\section{Procedure}

The procedure was identical to that of Experiment 1, with the exception that the FT 30 -sec schedule was replaced by RT $30-\mathrm{sec}$ schedules. On an RT 30-sec schedule, the probability that the UCS would be presented at any second in the trial was 1 in $30(.0333)$. To eliminate trials that might be extremely long, an arbitrary restriction of $100 \mathrm{sec}$ as the longest trial was imposed.

\section{Resuits}

Figure 3 presents the intratrial distributions of front and rear rates of activity for all subjects in the last five sessions of each motivational condition. Rates of activity are plotted as a function of time since the UCS, represented in thirty-four 3 -sec bins. To correct for the unequal bin frequencies inherent in the random schedule, rates are subjected to a conditional probability transformation and expressed as "rate per opportunity." The distributions of front and rear activity are not as smooth as they were in the FT procedure of Experiment 1, because averaging over the variable-trial lengths of RT schedules is based upon a decreasing number of instances of the bins furthest from reinforcement.

As expected, all animals in both groups showed uniform distributions of front and rear activity in both food and water conditions. Again, for 5 of the 6 animals, overall activity was higher in the food condition than in the water condition (Wilcoxon test: $T+=20, p<.03$ ). Activity was usually concentrated in the front, and the exceptions to this bore no consistent relationship to condition or group. Rates in the food condition were lower in the W-F group than in the F-W group (Mann-Whitney: $n 1=n 2=3, U=0, p<.05$ ). This might be a carry-over effect from the water phase, in which rates of activity were quite low.

Statistical comparison of rates of activity in Experiments 1 and 2 showed that rates were significantly higher in Experiment 2 than in Experiment 1 in the food condition (Mann-Whitney: $n 1=n 2=6, U=3, p<.015$ ) but not in the water condition (Mann-Whitney: $U=7$, $p<.09$ ).

\section{Discussion}

This experiment examined differences between foodand water-induced movement patterns on a schedule in which the UCS could not be predicted on the basis of time or an exteroceptive stimulus. The UCS probability did not change through the trial (except at the 100th sec) and therefore no taxic (directed) behavior was expected to occur. Indeed, both food and water presentations produced flat distributions of activity, with no changes 


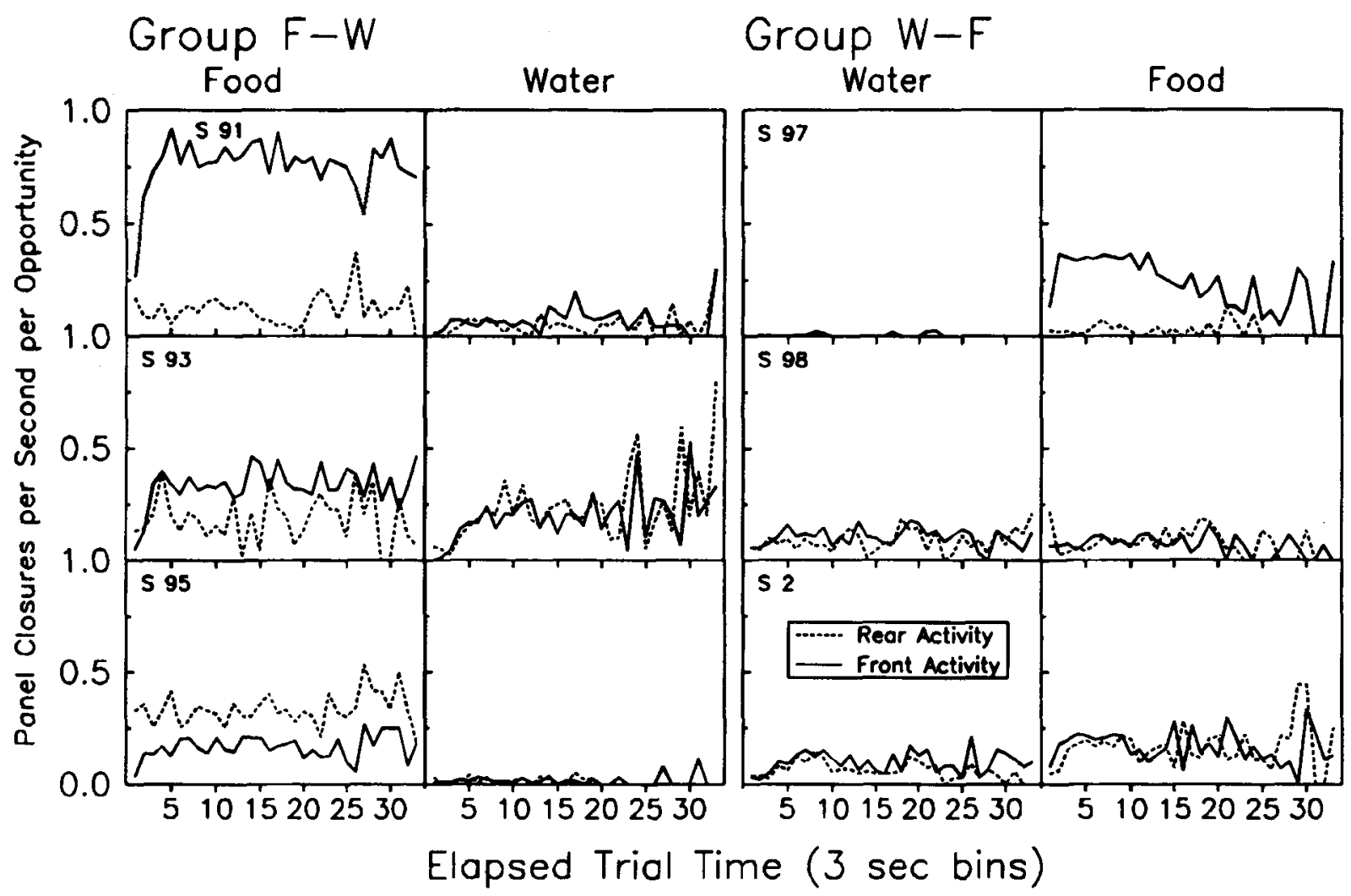

Figure 3. Rates (panel closures/second/opportunity) of front and rear activity plotted as a function of time since the UCS, represented in 3-sec bins, for each of the subjects in the F-W and W-F groups, in both motivational conditions. Each graph represents the average of all trials of the last five sessions (Sessions 11-15) in each condition. Averages for each 3-sec bin were calculated by summing all occurrences of frontor rear-panel closures during that bin over all trials of the last five sessions and dividing by the number of times that bin occurred. Response rates are corrected for differing bin frequencies by a "per opportunity" condition probability transformation.

within the trial. Despite the apparent elimination of taxic behaviors, the food procedure induced markedly higher rates of activity than the water procedure. And despite the elimination of signals that predicted the occurrence of UCS presentations, rates of activity in the water condition did not match the levels induced by food presentations. It appears that the results of Experiment 1 were confirmed. Although water deliveries may have induced slightly higher rates of kinesic behavior, when predictability was eliminated from the schedule, the rates were still quite low.

Overall, the findings of this experiment are usefully viewed from the behavior-system perspective (Timberlake, 1983a; Timberlake \& Lucas, 1985). Intermittent food presentations activate food-related foraging patterns. Since the schedule did not involve increases or decreases in reinforcement probability associated with time lapsing or specific stimuli, the behavior that should be observed is movement patterns that resemble the natural food-seeking behavior without the occurrence of systematic fluctuations in the trial. Indeed, in response to unpredictable food presentations, pacing was observed that was evenly distributed through the ISI. The water-seeking behavioral system does not involve much locomotor searching movement probably because the chances of detecting water in nature are not much enhanced by local perambulation. In response to random water presentations, not much movement should be observed, which was, in fact, the case.

A remaining possibility is that the apparent differences between food- and water-motivated behavior are simply the result of different levels of motivation induced by our procedures. This possibility will be discussed in the General Discussion below.

\section{GENERAL DISCUSSION}

In this study, terminal and interim behavior induced by food and water presentations was examined. The results seem to indicate that the terminal behavior, autoshaped keypecking, was similar with both appetitive stimuli. Latencies to initiate pecking and pecking rates were comparable. Although this might suggest that pecking is a generic response to localized UCS signals, as in "sign-tracking" (Hearst \& Jenkins, 1974), the higher frequency of very fast pecks observed with water presentations suggests a different pecking topography, a fact that is documented in the literature (Jenkins \& Moore, 1973).

The interim behavior produced by the two UCS types, however, was grossly different. Food presentations re- 
sulted in characteristic activity patterns that have been observed in many experiments in the past (Killeen, 1975; Matthews et al., 1990; Matthews \& Lerer, 1987; Staddon \& Simmelhag, 1971). With the FT schedule (Experiment 1), this pattern consisted of movement to the rear of the chamber near the beginning of the ISI and of pacing, which peaked near the midpoint of the trial. With the RT schedule (Experiment 2), it was primarily pacing, evenly distributed in the ISI, that was observed. In contrast, with water presentations, the RT schedule produced little activity and the FT schedule resulted in almost no interim behavior during the ISI, as defined by actuation of the floorboard.

Before concluding that food and water presentations induce different behavioral stereotypy, it should be noted that comparing across motivational systems is a problematic undertaking. Specifically, it is difficult to determine whether the obtained differences are inherent in the motivational system used or are due to some inequivalence in procedural or schedule parameters. One obvious such inequivalence could be in the deprivation level in the two motivational conditions. It has been shown that level of motivation is directly related to rates of induced behavior with food UCSs (see Falk, 1971; Killeen, 1975). With water UCSs, there is no information on the effects of the manipulation of that parameter on interim behavior. This issue is complicated further by the physiology of thirst. For instance, when water is not available, animals reduce their food intake also, which in turn diminishes their need for water (Hogan \& Roper, 1978).

It is unlikely, however, that possible differences in level of motivation could account for the profound differences in interim behavior that were observed, particularly in light of the similarity of the terminal behavior in the two conditions. Furthermore, most other studies have failed to find interim behavior such as hyperphagia, wheel-running, or activity in response to intermittent water presentations. Using rats, Timberlake and Lucas (1991) obtained similar results with a 24-h environment, different ISIs, and deprivation levels that were controlled by the animal.

The present results suggest that interim behaviors are, in fact, derivative of the same motivational mechanism that supports the effectiveness of the UCS. This contradicts the original position of Staddon and Simmelhag (1971) and Falk (1977), who suggested that qualitatively different UCSs should produce different terminal behavior but, if presented in a similar experimental setting, should produce similar interim behavior. In these experiments, the associative elements of terminal behavior (initiation and distribution of pecking) were similar with the two motivational stimuli, but keypecks differed in subtle ways that could reflect differences in consummatory response topography associated with the two UCSs. Food and water UCSs, however, differed substantially with respect to the induced interim behavior.

The approach described by Timberlake (1983a) and Timberlake and Lucas (1985) would appear to be more consistent with the present results. Their behaviorsystem view predicts that the type and rate of behaviors that arise in response to scheduled UCSs will depend on the behavioral conglomerate activated by the UCS used. The interim retreat and pacing observed in the food conditions correspond to the elements of the natural foodforaging patterns. Retreat may be related to the movement of a bird away from a depleted food source, and pacing may be related to visual search typical of pigeons in a food-rich environment. The absence of locomotor interim behavior with water UCSs could be predicted on the basis of the fact that the natural behavior regimen associated with water acquisition very likely does not include either movement away from a depleted patch or stereotyped visual ground search. Water is perhaps better found through aerial search, a behavior not likely to emerge in a standard experimental chamber. In any case, because water sources are more conspicuous and abundant than food sources, there may have been little selective pressure for a structured ground locomotor behavior system for water acquisition.

Killeen and Fetterman (1988) have suggested that "timing," or in this case the latency of onset of terminal keypecking on FT schedules, is mediated by the use of interim activities as discriminative stimuli. The almost identical onset of keypecking with or without preceding interim behavior would seem to challenge this theoretical assumption.

The present research also indicates that the temporal distribution of behavior in the ISI is mediated by common conditioning mechanisms. The initiation of keypecking near the trial midpoint in both motivational conditions indicates that type of UCS did not influence when the ramp stimulus became excitatory. The absence of retreat in the water condition, on the other hand, suggests the possibility that associative inhibition may not be common to the two motivational mechanisms. Retreat and other post-UCS behaviors have been shown to be under the control of inhibitory conditioned stimuli signaling low UCS probability (Hearst, Bottjer, \& Walker, 1980; Kaplan, 1984). It remains unclear if the absence of retreat in the water condition occurs because of a lack of inhibitory conditioning or because of a lack of a behavioral expression of inhibition. The emergence of some retreat behavior, however little, in the water condition of the F$\mathrm{W}$ group (Experiment 1) would suggest that inhibitory conditioning occurs with both food and water UCSs.

\section{REFERENCES}

Allan, R. W., \& MatThews, T. J. (1989). Comparative effects of food and water deprivation on movement patterns in the pigeon (Columba livia). Behavioural Processes, 20, 41-48.

Bellingham, W. P., Wayner, M. J., \& Barone, F. C. (1979). Schedule induced eating in water deprived rats. Physiology \& Behavior, 23, $1105-1107$.

Boakes, R. A., Poll, M., Lockwood, M. J., \& Goodall, G. (1978). A study of misbehavior: Token reinforcement in the rat. Journal of the Experimental Analysis of Behavior, 29, 115-134.

CAMPBELI, K. I., \& OEI, T. P.S. (1986). Failure to demonstrate schedule- 
induced hyperphagia with a fixed time 1 -minute water delivery schedule. Physiology \& Behavior, 36, 939-944.

Carlisle, H. J., Shanab, M. E., \& Simpson, C. W. (1972). Scheduleinduced behaviors: Effects of intermittent water reinforcement on food intake and body temperature. Psychonomic Science, 26, 35-36.

Davey, C. G. L., \& Cleland, G. G. (1982). Topography of signal centered behavior in the rat: Effects of deprivation state and reinforcer type. Journal of the Experimental Analysis of Behavior, 38, 291304.

FaLK, J. L. (1971). The nature and determinants of adjunctive behavior. Physiology \& Behavior, 6, 577-588.

FALK, J. L. (1977). The origin and functions of adjunctive behavior. $A n$ imal Learning \& Behavior, 5, 325-335.

FERSTER, C. B., \& SKINNER, B. F. (1957). Schedules of reinforcement. New York: Appleton-Century-Crofts.

Hearst, E., Bottuer, S. W., \& Walker, E. (1980). Conditioned approach-withdrawal behavior and some signal-food relations in pigeons: Performance and positive vs. negative "associative strength." Bulletin of the Psychonomic Society, 16, 183-186.

Hearst, E., \& Jenkins, H. M. (1974). Sign-tracking: The stimulusreinforcer relation and directed action. Austin, TX: Psychonomic Society.

Hogan, J. A., \& Roper, T. J. (1978). A comparison of the properties of different reinforcers. In J. S. Rosenblatt, R. A. Hinder, C. Beer, \& M. C. Bushnell (Eds.), Advances in the study of behavior (Vol. 8, pp. 155-255). New York: Academic Press.

Innis, N. K., Reberg, D., ManN, B., Jacobson, J., \& Turton, D. (1983). Schedule-induced behavior for food and water: Effects of interval duration. Behavioral Analysis Letters, 3, 191-200.

Innis, N. K., Simmelhag-Grant, V. I., \& Staddon, J. E. R. (1983). Behavior induced by periodic food delivery: The effects of interfood interval. Journal of the Experimental Analysis of Behavior, 39, 309. 322.

Jenkins, H. M., \& Moore, B. R. (1973). The form of the autoshaped response with food or water reinforcers. Journal of the Experimental Analysis of Behavior, 20, 163-181.

KAPLAN, P. S. (1984). Importance of relative temporal parameters in trace autoshaping: From excitation to inhibition. Journal of Experimental Psychology: Animal Behavior Processes, 13, 113-126.

KILLEEN, P. [R.] (1975). On the temporal control of behavior. Psychological Review, 82, 89-115.

KilleEN, P. R., \& Fetierman, J. G. (1988). A behavioral theory of timing. Psychological Review, 95, 274-295.

KING, G. D. (1974). Wheel running in the rat induced by a fixed-time presentation of water. Animal Learning \& Behavior, 2, 325-328.
Matthews, T. J., Bordi, F., \& Depollo, D. (1990). Schedule-induced kinesic and taxic behavioral stereotypy in the pigeon. Journal of Experimental Psychology: Animal Behavior Processes, 16, 335-345.

Matthews, T. J., \& LeRER, B. E. (1987). Behavior patterns in pigeons during autoshaping with an incremental conditioned stimulus. Animal Learning \& Behavior, 15, 69-75.

NEvin, J. A. (1984). Pavlovian determiners of behavioral momentum. Animal Learning \& Behavior, 12, 363-370.

Reberg, D., InNis, N. K., ManN, B., \& Eizenga, C. (1978). "Superstitious" behavior resulting from response-independent presentations of food or water. Animal Behaviour, 26, 507-519.

Reid, A. K., Vasquez, P. P., \& Rico, J. A. (1985). Schedule induction and the temporal distributions of adjunctive behavior on periodic water schedules. Animal Learning \& Behavior, 13, 321-326.

Staddon, J. E. R. (1977). Schedule induced behavior. In W. K. Honig \& J. E. R. Staddon (Eds.), Handbook of operant behavior (pp. 125152). Englewood Cliffs, NJ: Prentice-Hall

Staddon, J. E. R., \& Ayres, L. S. (1975). Sequential and temporal properties of behavior induced by a schedule of periodic food delivery. Behaviour, 54, 26-49.

Staddon, J. E. R., \& Simmelhag, V. (1971). The "superstition" experiment: A re-examination of its implications for the principles of adaptive behavior. Psychological Review, 78, 3-43.

TimberLAKE, W. (1983a). The functional organization of appetitive behavior: Behavior systems and learning. In M. D. Zeiler \& P. Harzem (Eds.), Advances in the analysis of behaviour: Biological factors in learning (pp. 177-221). Chichester, U.K.: Wiley.

Timberlake, W. (1983b). Rats' responses to a moving object related to food and water: A behavior-systems analysis. Animal Learning $\&$ Behavior, 11, 309-320.

Timberlake, W., \& Lucas, G. A. (1985). The basis of superstitious behavior: Chance contingency, stimulus substitution, or appetitive behavior? Journal of the Experimental Analysis of Behavior, 44, 279-301

Timberlake, W., \& Lucas, G. A. (1991). Periodic water, interwater interval, and adjunctive behavior in a 24-hour multiresponse environment. Animal Learning \& Behavior, 19, 355-360.

WEThERINGTON, C. L., \& RiLEY, A. L. (1985). Differences in food consumption under intermittent and continuous schedules of water delivery. Animal Learning \& Behavior, 13, 331-337.

(Manuscript received March 10, 1993; revision accepted for publication May 3, 1995.) 